\title{
Making global warming public property
}

There is a long way to go before the research community concerned with the behaviour of the Earth's atmosphere will win general acceptance of its message that global warming is serious. Less zeal and more guile would help.

THE Ditchley Foundation, the British charity whose chief asset is the right to use a splendid tudor manor house in Oxfordshire as a conference centre, has embraced global warming. Last weekend, it invited a group of people from mixed backgrounds (roughly a third each from Britain, the United States and elsewhere - mainland Europe and Japan) to make sense of this vexed issue. The chairman was Sir Crispin Tickell, until last summer the British Ambassador to the United Nations, now the Master of Green College, Oxford, who has done more than most people to put global warming on the international agenda. The meeting had been timed closely to precede the intergovernmental conference that opens in Washington on 4 February, at which a start will be made on the negotiation of a greenhouse convention.

What can a gathering like this suggest about the likely outcome of the eighteen months of negotiations that begin next month? Chiefly, that the way ahead is bound to be difficult. Even among a small group of people self-selected by earlier declarations of interest in the field, perspectives are so different as sometimes to seem orthogonal to each other.

How much more difficult must it be to win agreement among government delegations representing diametrically opposed interests? Some dispute the science of the problem. Some favour adaptation to climate change, and others its avoidance. Some developing countries may (as foretold last weekend) assert that global warming is a story told by the industrialized rich to prevent the development of the rest of the world.

What follows is an impression of an enthralling, but also admonitory, meeting; the rules of these occasions forbid ordinary reporting, in particular the attribution of even the most arresting statements to those who made them.

First, there is a semantic question: if the predictions of the trend of average temperature generated by the computer models of global climate are always attended by large uncertainties, what credence can be given to the simple story of global warming? In particular, if the uncertainties are so great, might it not be that extra carbon dioxide could lead to global cooling? Plainly it will not be easy to persuade the world at large that the greenhouse effect that has, since at least the Precambrian, made the surface of the
Earth habitable, is certain to work in the same direction when the concentration of greenhouse gases is artificially increased.

The modellers themselves exude a sense of injury in this connection. When the case is so clear, why are the sceptics so generously given a hearing? This is not just a matter of public relations (however nicely that phrase is meant), but of the attention and criticism people's work is given when, perhaps against their expectations, it turns out to be potentially of great practical significance. Those who happened, in the $1950 \mathrm{~s}$, to be working on the genetic effects of small doses of ionizing radiation quickly learned this lesson, often with chagrin. There seems to be a danger that at least some climatologists have not yet learned that those who question their conclusions, even without experience in the field, are not necessarily fools. (Others, it must be said, have learned to be as judicious as the Sphinx.)

Especially because the economic consequences of global warming are so great, as measured by the costs either of avoidance or adaptation, there is a case for asking that the modellers should go out of their way to give the sceptics a patient answer. If somebody argues, for example, that a more powerful greenhouse will, by increasing the circulation of water vapour in the lower troposphere, make the atmosphere dryer at greater altitude and thus remove water vapour (a greenhouse gas) from the region at which it is most effective, he should be given a more courteous hearing than is now usual.

It would also strengthen the case of the climatologists if people who model complicated systems other than the Earth's climate were given access, as constructive critics, to the models on which current predictions are based. Perhaps the outstanding precedent is that of the British Treasury which, almost two decades ago, made its economic model available to independent economists, many of them sceptical of its performance. Many who came to scoff were, as a consequence, converted. More practically, it is entirely possible that the next generation of computer models of the Earth's climate would be developed more effectively if there were a more vigorous exchange with those working in other fields.

What does appear beyond dispute is that the moderate case for the global warming story has been badly served by the manner in which it has been told.
Some would say that too much has been published, but that cannot by definition be true. But it is significant that documents that should have been influential have often been published so untidily that even sympathetic readers have been dismayed by them.

This applies to last summer's reports from the Intergovernmental Panel on Climate Change (IPCC), which made their way into print as successive drafts, often as drafts of what are called "executive" summaries. By all accounts, the report on which the US National Academy of Sciences has been working for the past eighteen months, and which had been intended for publication before next month's meeting in Washington, will avoid these difficulties even if its publication is delayed until after the conference is over.

The missing ingredient is a means by which even the research community can make sense of the original research related one way or another to global warming that now sees the light of day. The ideal would be a continuing authoritative review of the original literature. There is a precedent of a kind - the occasional volumes put out by the United Nations committee called UNSCEAR (the Scientific Committee on Energetic and Atomic Radiation), which have been powerful reinforcements of the radiation safety standards. But because some such assessment mechanism will be needed if ever there is a greenhouse convention, the sooner it is set up, the better.

Sadly, the same device would not suffice for the more difficult questions that will have to be answered in the years ahead. Global warming will affect not simply physical and biological systems (sea level and agriculture, for example), but the whole fabric of society. But who, at this stage, would guess at the extent to which substantially higher costs for surface transport will change the character of industrialized societies, and affect their productivity? Or how far an effective greenhouse convention will require that the world's population should also be regulated, and how? These, it should be acknowledged, are the real uncertainties, and the true impediments to decision. Sadly, the global warming community is over-zealous in its conviction that, with the physics of the atmosphere reasonably well understood, other difficulties should be swept aside in the pursuit of agreement.

John Maddox 